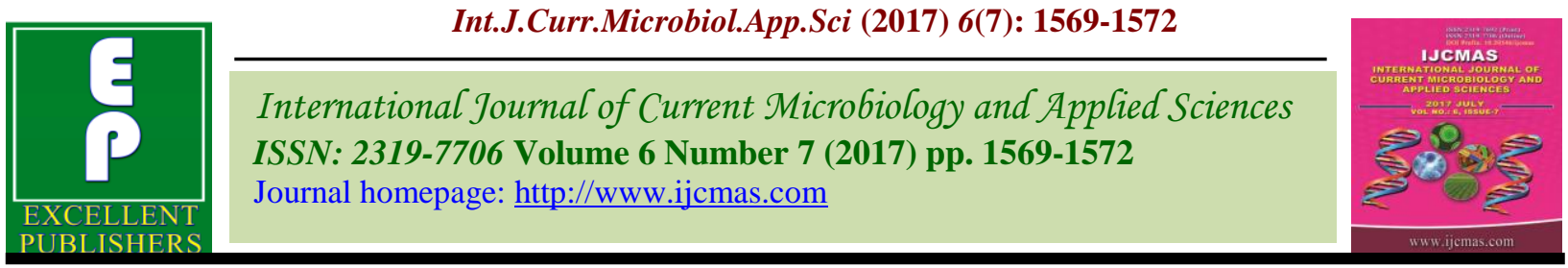

Original Research Article

https://doi.org/10.20546/ijcmas.2017.607.188

\title{
Edible Bioplastic with Natural pH Indicators
}

\author{
Harsh Patel, Sudarshan Seshadri and J.R. Parvathi*
}

School of Biotechnology and Bioinformatics, D.Y. Patil University, Level 5, Sector 15, Plot No. 50, CBD Belapur, Navi Mumbai, Maharashtra 400614, India

*Corresponding author

\begin{tabular}{|c|c|}
\hline & A B S T R A C T \\
\hline Keywords & \\
\hline $\begin{array}{l}\text { Bio-degradable, } \\
\text { Starch based } \\
\text { bioplastic, Food } \\
\text { packaging, } \\
\text { Intelligent } \\
\text { packaging, Natural } \\
\text { pH indicators. }\end{array}$ & \multirow{3}{*}{$\begin{array}{l}\text { The rationale of this elementary work was to develop starch based bio-coat } \\
\text { for food items using permutation combination of starch of different sources } \\
\text { (corn, potato, tapioca) and various plasticizers (glycerine, rice bran oil, } \\
\text { sesame oil, castrol oil, soya bean oil and olive oil). An eco-friendly } \\
\text { alternative to conventional petro-plastic polymer with a futuristic } \\
\text { application as edible food wraps was intended as the outcome. } \\
\text { Amalgamation of corn, tapioca and potato starch in even proportions, } \\
\text { generated the finest bio-plastic sheet; glycerine was chosen as the ideal } \\
\text { plasticizer as vegetable oils yielded brittle bioplastics. Inclusion of red } \\
\text { cabbage extract to this bioplastic formulation exhibited colour change with } \\
\text { pH variation, a simple panacea for spoilage detection. }\end{array}$} \\
\hline Article Info & \\
\hline $\begin{array}{l}\text { Accepted: } \\
\text { 19 June } 2017 \\
\text { Available Online: } \\
10 \text { July } 2017\end{array}$ & \\
\hline
\end{tabular}

\section{Introduction}

Packaging is a quintessential entity of today's market having a broad niche covering commodities to food items. Plastic reverberates as the ideal packaging in this new era of modernization; the same also accounts as the most dreaded environmental pollutant because of their sheer lack of degradability. An alternative to this synthetic polymer that features both sustainability and complete degradation is the need of this hour. This has spearheaded the research towards exploring natural polymers; their abundance, availability, non-toxic effect and easy degradation adds on to the appeal and choice for the same as alternative packaging material. Bioplastics, derived from biological sources either from vegetable stock or microbes is the absolute answer for this scenario (Saharan et al., 2012). The next thing and advancement in the world of packaging is active and intelligent packaging (De Johng et $a l ., 2005)$ with former having inherent feature to provide extra protection to the items packed whereas latter is involved in signaling the consumers about the quality of the items packed. Among the advances in intelligent packaging, one of the most interesting and one that renders customers with an ease to assess the freshness visually of the same are colour changing packages. The basis of this 
active packaging in changing colour could be triggered change in temperature (thermo chromic materials), irradiation from light (photochromic materials), application of an electric potential (electro chromic materials) or $\mathrm{pH}$ change (Lee et al., 2008; Hong et al., 1999). An attempt to develop colour changing bio-plastic with red cabbage extracts to provide a proof of concept that could lead to futuristic development of colour changing bio-wraps or bio-dips for edible items as means for detecting spoilage was attempted here.

\section{Materials and Methods}

\section{Standardization of ingredients for bioplastic preparation}

The basic ingredients for starch-based bioplastics are starch, vinegar, plasticizer and water. Starch from three different sources; corn, potato and tapioca were procured. A total of 8 trails were conducted; 7 with varying plasticizers and one without any plasticizer (Table 1). Each set entailed of 3 type of starch source and a unique plasticizer. Castor oil, gelatin, glycerol, sesame oil, soya bean oil and olive oil were the array of plasticizers used for the study. For each of these sets, $15 \mathrm{gm}$ of each sugar, $5 \mathrm{ml}$ of vinegar and $300 \mathrm{ml}$ of water were kept constant, only $5 \mathrm{ml}$ of plasticizer was varied. For preparing bioplastic, first starch and water were mixed, stirred, followed by heating on a hot plate till the mixture started gelatinizing. After achieving the gelatinization of starch, about 5 $\mathrm{ml}$ of plasticizer and vinegar were added. This mixture was placed for $10 \mathrm{~min}$ in hot water bath and were spread on an even glass surface with TLC glass spreader adjusted to make thin layer $2 \mathrm{~mm}$ diameter sheets on a smooth and even surface. These sheets were allowed to dry at room temperature till it was no longer sticking to the surface of layering. After analyzing the quality of plastic based on their smoothness and elasticity, the best plasticizer was selected. Then next step was to try for the permutation combination of sugars to finalize the best combination for preparation of bioplastic. Equiamount of starch source were weighed for the same keeping the rest constant as mentioned for the previous sets (S-1 to $\mathrm{S}-8$ ).

\section{Intelligent packing with red cabbage extract}

$250 \mathrm{gm}$ of the red cabbage was sliced into small pieces and boiled in low heat for $15 \mathrm{~min}$ in $500 \mathrm{ml}$ distilled water. The extract was filtered and again autoclaved to prevent any fungal growth during the preparation of bioplastics. The best suitable permutation combination was used for this process, the starch components were mixed with $300 \mathrm{ml}$ of red cabbage extract instead of distilled water in a glass vessel. The mixture was heated in a hot plate till the mixture started gelatinizing or melting. After achieving the gelatination of starch about $5 \mathrm{ml}$ glycerin as plasticizer was added and placed for $10 \mathrm{~min}$ in hot water bath following by layering the mixture. The layering was executed with Thin layer plating The bioplastic thus prepared were cut into equal square slices $(1 \mathrm{~cm} \times 1 \mathrm{~cm})$, two to three drops of citric acid, $0.5 \mathrm{~N} \mathrm{HCl}, 2 \mathrm{M} \mathrm{KOH}$ and $1 \mathrm{~N} \mathrm{NaOH}$ as well as solutions ranging from $\mathrm{pH} 1$ to 14 , was added respectively onto each sheets and the colour change was recorded

\section{Results and Discussion}

Among 24 combinations tried with singular composition of starch with different plasticizers, only the S-2 series (S-2-1 to S-24) gave smooth sheets. The bioplastic sheets (S1 series) without plasticizer were poor and brittle; soft sheets of bioplastics that were easily breakable with even the lightest of pull were produced when gelatin was used as the plasticizer (S3 series). 
Int.J.Curr.Microbiol.App.Sci (2017) 6(7): 1569-1572

Table.1 Trials of sugar and plasticizer combination

\begin{tabular}{|c|c|c|c|c|c|c|c|c|c|c|c|}
\hline \multicolumn{12}{|c|}{ Single sugar (S Series) } \\
\hline Trial & Starch & $\mathrm{Pz}$ & Trial & Starch & $\mathrm{Pz}$ & Trial & Starch & $\mathrm{Pz}$ & Trial & Starch & $\mathrm{Pz}$ \\
\hline S-1-1 & Corn & $\mathrm{N}$ & S-3-1 & Corn & $\mathrm{Ge}$ & S-5-1 & Corn & RB & S-7-1 & Corn & $\mathrm{CA}$ \\
\hline S-1-2 & Potato & $\mathrm{N}$ & $S-3-2$ & Potato & $\mathrm{Ge}$ & $S-5-2$ & Potato & $\mathrm{RB}$ & $S-7-2$ & Potato & $\mathrm{CA}$ \\
\hline$S-1-3$ & Tapioca & $\mathrm{N}$ & $S-3-3$ & Tapioca & $\mathrm{Ge}$ & $S-5-3$ & Tapioca & $\mathrm{RB}$ & $S-7-3$ & Tapioca & $\mathrm{CA}$ \\
\hline S-2-1 & Corn & G & S-4-1 & Corn & $\mathrm{Ol}$ & S-6-1 & Corn & SE & S-8-1 & Corn & SO \\
\hline S-2-2 & Potato & G & S-4-2 & Potato & $\mathrm{Ol}$ & S-6-2 & Potato & SE & S-8-2 & Potato & SO \\
\hline $\mathrm{S}-2-3$ & Tapioca & G & $\mathrm{S}-4-3$ & Tapioca & $\mathrm{Ol}$ & S-6-3 & Tapioca & SE & S-8-3 & Tapioca & $\mathrm{SO}$ \\
\hline \multicolumn{12}{|c|}{ Combination (D series) } \\
\hline D 1 & \multicolumn{3}{|c|}{ Corn+Potato } & D2 & $\mathrm{Cc}$ & apioca & \multirow{2}{*}{\multicolumn{2}{|c|}{ D3 }} & \multirow{2}{*}{\multicolumn{3}{|c|}{ Tapioca+Corn }} \\
\hline D4 & \multicolumn{3}{|c|}{ Tapioca+Potato } & D5 & \multicolumn{2}{|c|}{ Corn + potato+Tapioca } & & & & & \\
\hline
\end{tabular}

Starch of different source and grade were procured; Corn, starch and extra pure starch from Chemical International, Mumbai whereas potato and tapioca starch from SRL and Plantain banana powder (Bana rich, Cochin Ayurvedic center). Among the different plasticizer tried, glycerine was obtained from Chemical International; s well as red cabbage (the source of $\mathrm{pH}$ indication) where procured from local groceries store.

Plasticizer: Pz; N: nothing was added; G: Glycerol; Ge: gelatin; Ol: Olive oil; RB: Rice Bran oil; SE: Sesame Oil, CA: Castor Oil; SO: Soya bean oil

Fig.1 Colour change observed in bio-plastic with red cabbage extracts

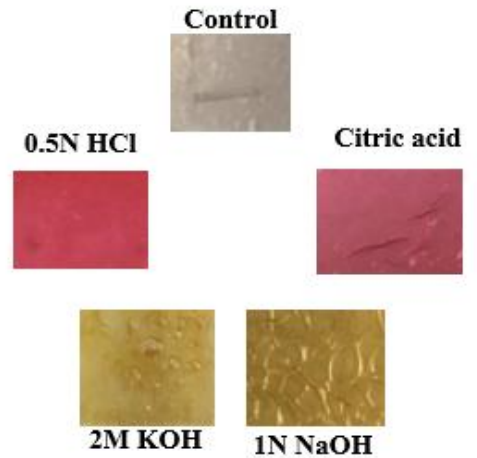

Sheets turned to be hard, shapeless and brittle in all the trials where vegetable oil ( $\mathrm{S} 4$ to $\mathrm{S} 8$ series) was used as plasticizer. Glycerol was found to be the ideal plasticizer, providing stretchable, smooth, transparent and good quality bioplastics. Potato starch plastics appeared the most clearest or transparent followed by corn, and tapioca. All the D series showed smooth transparent bioplastics but the steadiest yet stretchable and wrap-able quality were given by D5 (all sugars) followed by D4 (combination of tapioca and potato). Subsequently D5 combination with red cabbage extracts showed visible colour change. Red cabbage extract comprise of anthocyanin, natural water soluble $\mathrm{pH}$ indicators that give reddish pink to violet colour in acidic conditions ( $\mathrm{pH} \mathrm{1-6)} \mathrm{whereas}$ in basic or alkaline condition ( $\mathrm{pH}$ 8-14) colour change from blue to green and finally and to yellow at extreme alkaline condition (Chigurupati et al., 2002). In the current study the change in colour was observed [Fig 1] in extreme acidic (till $\mathrm{pH}$ 2) and alkaline conditions ( $\mathrm{pH}$ 11-14). Increase in concentration of red cabbage extracts in the bioplastic preparation can help in defining the $\mathrm{pH}$ variability with much clarity, nevertheless the colour change observed here proved that the bioplastics coupled with these natural $\mathrm{pH}$ 
indicator has applicability. This proves as a simple and smart method of signaling consumers the quality of the food that is dependent of $\mathrm{pH}$ change.

\section{References}

Brockgreitens, J., Abdennour, A. 2016. Responsive Food Packaging: Recent Progress and Technological Prospects. Comprehensive Rev. Food Sci. Food Safety, 15(1): 3-15, DOI: 10.1111/15414337.12174.

Chigurupati, N., Saiki, L., Gayser, C., Dash, A.K. 2002. Evaluation of red cabbage dye as a potential natural color for pharmaceutical use. Int. J. Pharmacol., 241(2): 293-299.
De Johng, A.R., Boumans, H., Slaghek, T., Van Veen, J., Rijk, R., Van Zandvoort, M. 2005. Active and intelligent packaging for food: Is it the future? Food Additives and Contaminants, 22(10): 975 - 979.

Hong, S.I., Park, W.S. 1999. Development of color indicators for kimchi packaging. J. Food Sci., 64: 255-257.

Lee, D.S., Yam, K.L., Piergiovanni, L. 2008. Food Packaging Sci. Technol., Boca Raton, FL: Taylor and Francis Group., pp. 445- 473.

Saharan, B.S., Sharma, D. 2012. BioplasticsFor Sustainable Development: A Review. Int. J. Microbial Res. Technol., 1(1): 11-23.

\section{How to cite this article:}

Harsh Patel, Sudarshan Seshadri and Parvathi, J.R. 2017. Edible Bioplastic with Natural pH Indicators. Int.J.Curr.Microbiol.App.Sci. 6(7): 1569-1572. doi: https://doi.org/10.20546/ijcmas.2017.607.188 